J. Lake Sci. (湖泊科学), 2012, 24(5): 679-686

http: //www. jlakes. org. E-mail : jlakes@niglas.ac.cn

(C) 2012 by Journal of Lake Sciences

\title{
基于径流分析的淮河流域汛期旱涝急转研究"
}

张水锋, 张金池 ${ }^{* *}$, 闵俊杰, 张增信, 庄家尧, 林 杰

(南京林业大学江苏省林业生态工程重点实验室,南京 210037)

摘 要: 本文基于淮河流域吴家渡水文监测站 1950-2007 年月径流量资料, 通过定义长、短周期径流早涝急转指数, 分 析了淮河流域汗期径流早涝急转现象 (分旱转涝和涝转旱两种类型), 研究结果表明: 1) 长周期径流旱涝急转在 1986 年 以前发生次数较多,而 1986 年以后发生次数相对较少;2) 各相邻月间的短周期早涝急转的年际振荡以 6-7 月最多,且其 长期变化规律与长周期旱涝急转年际振荡变化相似; 3 长、短周期旱涝急转频次呈现不断减少的趋势, 但全旱和全涝频 次则有增加的趋势;4)2000s 汛期长周期早转涝、短周期 6-7 月旱转涝有逐渐增加的趋势, 分析认为这种旱涝急转变化 是导致淮河流域汗期径流量增加的主要原因之一.

关键词: 径流量; 旱涝急转;淮河流域; 汗期

\section{Drought-flood abrupt alternation based on runoff in the Huaihe River Basin during rainy season}

ZHANG Shuifeng, ZHANG Jinchi, MIN Junjie, ZHANG Zengxin, ZHUANG Jiayao \& LIN Jie ( Jiangsu Key Laboratory of Forestry Ecological Engineering, Nanjing Forestry University, Nanjing 210037, P. R. China)

\begin{abstract}
Based on the monthly runoff data during 1950 - 2007 at Wujiadu Hydrologic Station in the Huaihe River Basin, the drought-flood abrupt alternation phenomena(including drought to flood and flood to drought) based on runoff was analyzed during the main rainy season(MJJA) by using long-and short-cycle runoff drought-flood abrupt alternation index (RDFAI). The results are as follows: 1) the frequency of long-cycle runoff drought-flood abrupt alternations was higher in the period before 1986, and then decreased after the late $1980 \mathrm{~s} ; 2$ ) Inter-annual changes of the short-cycle runoff drought-flood abrupt alternation phenomena between the adjacent months varied from each other, with the change between June and July being the most obvious one, and the long-term changes are similar to that of the long-cycle runoff drought-flood abrupt alternation phenomena; 3 ) Both the occurrence of long-and short-cycle runoff drought-flood abrupt alternation phenomena showed decreasing trends during the past 57 years, however, the total drought and total flood phenomena were on the rise; 4) During the 2000s, both the long-cycle and short-cycle runoff drought to flood abrupt alternation in June and July increased, and this might be one of the major reasons for the runoff increase during the rainy season at the same period.
\end{abstract}

Keywords: Runoff; drought-flood abrupt alternation; Huaihe River Basin; rainy season

淮河流域地处我国东部, 位于长江以北、黄河以南, 总面积约 $27 \times 10^{4} \mathrm{~km}^{2}$. 在气候上属于南北气候过渡 地带, 为半湿润、半干旱气候. 该流域受东亚季风影响较大, 降水时空分布非常不均匀, 易发生旱涝 ${ }^{[1]}$. 淮河 流域有耕地面积 $1333 \mathrm{hm}^{2}$, 是我国重要的粮棉生产基地. 12 世纪以后, 受黄河长期夺淮的影响, 淮河水系遭 到巨大破坏, 人海出路受阻, 干支流洪水排泄不畅, 水旱灾害频繁, “大雨大灾, 小雨小灾, 无雨旱灾”, 流域经 济受到极大影响. 据不完全统计, 在 1949-2006 年的 58 a 间, 安徽省旱涝急转典型年份达 $21 \mathrm{a}$, 占统计年份 数的 $36 \%$. 而淮北地区和大别山区高达 $17 \mathrm{a}$, 占安徽省旱涝急转年份的 $81 \%{ }^{[2]} .2005$ 年 6 月上旬到 7 月上

* 林业公益性行业科研专项项目 (201104005)、水利公益科研专项项目 (200901042) 和国家自然科学基金项目 (40801015) 联合资助. 2011-10-10 收稿;2012-03-06 收修改稿. 张水锋,男, 1986 年生, 硕士研究生; E-mail: zsf0511@126. com.

** 通信作者;E-mail: zhang8811@ njfu. edu. cn. 
旬,在短短的一个多月内, 安徽省先是出现全省性严重干旱, 随后沿淮淮北地区又发生了严重洪涝灾害, 形 成了旱涝急转的严峻局面. 2006 年 6 月底到 7 月初也出现了旱涝急转,截至 7 月 4 日 $16: 00$, 强降雨导致沿 淮淮北及皖东累计受涝面积 $3266.7 \mathrm{~km}^{2}$. 旱涝急转也极易造成人员伤亡、水库垮坝等重大经济损失. 因此, 对于淮河流域旱涝规律的探究显得十分重要.

气候变化已成为当今世界最普遍关注的环境问题之一. 由于气候变化的影响, 导致旱、涝等极端水文事 件频繁发生,引起了国际社会的普遍关注 ${ }^{[3-8]}$. 旱涝异常直接影响人类的生命和生活, 严重影响社会和经济 的发展. 旱涝异常主要分为旱涝并存和旱涝急转, 其中旱涝并存又由不同周期尺度的旱涝急转所构成 ${ }^{[9]}$. 在 国际上, Karl 等 ${ }^{[10]}$ 和 Dai 等 ${ }^{[11]}$ 在旱涝异常与全球气候变化方面做了相应研究; 在国内, 早在 $1960 \mathrm{~s}$, 陶诗言 等 ${ }^{[12]}$ 就研究了夏季江淮流域持久性旱涝现象的环流特征,并指出在江淮流域大水时期,表现在该年大气环 流上季节变化推迟一个月,而且在大水持续期间, 环流型式的稳定度也很显著. 近年来, 吴志伟等 ${ }^{[13-14]}$ 对正 常季风年夏季早涝急转特征做了研究分析,并指出华南 “旱涝并存、旱涝急转”夏季总雨量往往趋于正常, 季 节平均季风分布接近正常年份, 强“旱涝并存、旱涝急转”夏季易 “旱”且易 “涝”, 而弱“旱涝并存、旱涝急转” 夏季则较为 “风调雨顺”; 长江中下游地区夏季长周期旱涝急转与前期 2 月份南半球和北半球环状模存在显 著的负相关, 前期南半球和北半球环状模可以作为预测长江中下游地区长周期旱涝急转的一个前兆信号. 王胜等 ${ }^{[15]}$ 分析了淮河流域主汗期降水气候特征与 “旱涝急转” 现象, 结果表明淮河流域 “旱涝急转”现象频 繁发生,尤其是 2000 年以来频次显著增多. 唐明等 ${ }^{[16]}$ 探讨了沿海淮北地区早涝急转的气候成因,并指出该 区域近 $10 \mathrm{a}(1995-2005$ 年) 来暴雨频数、降水强度和短时干旱缺水概率所呈现的增加趋势是发生旱涝急转 的气候原因. 以往有关流域旱涝异常的研究, 大多是基于降水资料进行分析,而从径流量变化特征来分析流 域的旱涝急转特征还比较少见. 尤其径流是流域中气候和下垫面各种自然地理因素综合作用的产物,径流 量的大小将直接决定着流域的旱涝分布, 决定了洪水和干旱的变化. 因此, 本文尝试利用径流量资料来分析 淮河流域的旱涝急转的变化特征. 通过分析淮河流域汛期 (5-8 月) 内的长、短周期径流旱涝急转特征, 研 究淮河流域径流旱涝变化的特点, 准确把握抗旱防汛总体趋势, 以期为淮河流域抗旱防汛工作提供科学 依据.

\section{1 资料与方法}

\section{1 资料来源}

基于淮河流域的水文气象特点,定义每年的 5-8 月为淮河流域的汛期,月径流量数据来自淮河流域吴 家渡水文监测站,时间序列为 1950-2007 年. 在计算指数前进行了严格的质量控制, 剔除了错误值, 确保资 料的可利用性和可靠性.

\section{2 数据分析方法}

本文定义汛期长周期旱涝急转为 5-6 月和 7-8 月 (即旱和涝的尺度都为两个月, 5-6 月旱, 7-8 月 涝;或 5-6 月涝, 7-8 月旱), 短周期旱涝急转则以月为单位对 5-8 月进行分析.

采用线性趋势法、累积距平法等来分析径流随时间的变化与异常规律. 线性趋势法就是把气候要素写 成时间 $t$ 的线性函数 $x=\mathrm{a} t+\mathrm{b}, \mathrm{a} 、 \mathrm{~b}$ 为经验常数,其中 $\mathrm{a}$ 表示线性函数的斜率,即气候要素的线性趋势, $\mathrm{a}$ 为 正 (负) 表示增加 (减小) 趋势,零表示无变化趋势. 累积距平是一种常用的、由曲线直观判断变化趋势的方 法 ${ }^{[17]}$. 累积距平曲线呈上升趋势, 表示距平值增加, 呈下降趋势则表示距平值减小. 从曲线的明显上下起伏, 可判断其长期显著的演变趋势及持续性变化,甚至还可以诊断出发生突变的大致时间.

另外, 参考 $\mathrm{Wu}$ 等 ${ }^{[9]}$ 基于降水分析对旱涝急转的研究, 定义了径流旱涝急转指数 (Runoff Drought-Flood Abrupt Alternation Index, RDFAI), 分别有长周期径流旱涝急转指数和短周期径流旱涝急转指数, 共同来分 析淮河流域汛期内的径流旱涝变化特征.

长周期径流旱涝急转指数:

$$
\operatorname{RDFAI}=\left(R_{78}-R_{56}\right) \cdot\left(\left|R_{56}\right|+\left|R_{78}\right|\right) \cdot 1.8^{-\left|R_{88}+R_{88}\right|}
$$

式中, $R_{78}$ 为 7-8 月份标准化径流量, $R_{56}$ 为 5-6 月份标准化径流量. $\left(R_{78}-R_{56}\right)$ 为旱涝急转强度项, 
( $\left.\left|R_{56}\right|+\left|R_{78}\right|\right)$ 为旱涝强度项; $1.8^{-\left|R_{58}+R_{x}\right|}$ 是权重系数,作用是增加长周期旱涝急转事件所占权重,降 低全旱或全涝事件权重. 径流距平标准差小于 -0.5 为偏旱, 小于 -1 为显著偏旱; 而大于 0.5 为偏涝, 大于 1 为显著偏涝,介于 $-0.5 \sim 0.5$ 之间的属于径流量正常年份. 长周期 5-6 月、 $7-8$ 月径流距平标准差对应 的径流量旱涝划分标准见表 1 .

短周期径流旱涝急转指数:

$$
\operatorname{RDFAI}=\left(R_{j}-R_{i}\right) \cdot\left(\left|R_{i}\right|+\left|R_{j}\right|\right) \cdot 3.2^{-\left|R_{i}+R_{j}\right|}, \quad j=i+1(i=5,6 、 7)
$$

经测试选用 $3.2^{-\left|R_{i}+R_{i}\right|}$ 作为权重系数, 分别对 $5 、 6$ 月, $6 、 7$ 月, $7 、 8$ 月的月间旱涝急转指数进行计算 和分析. 短周期各月径流距平标准差对应的径流量 旱涝划分标准见表 2 .

\section{2 研究结果}

\section{1 淮河流域旱涝急转特征}

2.1 .1 长周期径流旱涝急转特征 高 RDFAI 年 7-8 月标准化径流量中有 $5 \mathrm{a}$ 大于 0.5 , 仅有 $1 \mathrm{a}$ 为 0.49 , 且有 $3 \mathrm{a}$ 大于 1 ,说明 6 个高 $R D F A I$ 年基本偏涝, $3 \mathrm{a}$ 显著偏涝,而 5-6 月距平中有 5 a 小于 -0.5 , 其中 2 a 接近 -1 ,显著偏旱, 3 a 略小于 -0.5 , 偏旱, 另外, 还有 $1 \mathrm{a}$ 标准化径流量略小于 0 ,表明该年径流量偏 小于多年平均水平; 低 $R D F A I$ 年 5-6 月标准化径流 量中 4 a 大于 0.5 , 偏涝, 2 a 略小于 0.5 , 接近偏涝, 而 7-8 月距平中 $4 \mathrm{a}$ 小于 -0.5 , 偏旱, $2 \mathrm{a}$ 略大于 -0.5 , 接近偏旱,其中, $5-6$ 月中 $4 \mathrm{a}$ 都是显著偏涝 (1964 年为特涝) , 7-8 月中 $1 \mathrm{a}$ 显著偏旱 (表 3 ). 另 外,高 RDFAI 年 7-8 月标准化径流量均大于 5-6 月径流量, 低 $R D F A I$ 年 7-8 月标准化径流量则均小 于 5-6 月径流量. 由此可见,高 RDFAI 对应着径流 的旱转涝, 低 RDFAI 对应着径流的涝转旱.

选取 6 个高 $R D F A I$ 年 $(1950 、 1965 、 1968 、 1982 、$ 1996 和 2007 年) 作为淮河流域汛期径流典型旱转涝 年; 在 6 个低 $R D F A I$ 中选取 5 个 (1959、1964、1971、 1973 和 1985 年) 作为淮河流域典型涝转旱年. 需要 说明的是, 在典型旱转涝年中, 1950 年 5-6 月的径 流距平不到 0.5 个标准差, 但考虑到 7-8 份径流距 平为 1.48 , 接近 1.5 个标准差, 异常明显; 以及 1996 年的 7-8 月份距平为 0.49 , 接近 0.5 个标准差, 且 5 -6 月份距平为 -0.69 , 小于 -0.5 , 较明显; 同时为 增加分析的样本数, 将这两年近似作为典型旱转涝 年. 另外, 同样也在典型涝转旱年分析中增加了 1959 年和 1971 年. 因此,淮河流域在 1950-2007 年期间 共发生 11 次典型旱涝急转现象.

长周期旱涝急转现象在 1950-1986 年期间表现为:典型旱转涝 $4 \mathrm{a}, 9.25 \mathrm{a} /$ 次,典型涝转早 $5 \mathrm{a}, 7.4$ $\mathrm{a} /$ 次. 涝转旱频次多于旱转涝频次. 1987-2007 年则表现为: 典型旱转涝 $2 \mathrm{a}, 10.5 \mathrm{a} /$ 次, 无典型涝转旱年. 1987-2007 年旱涝急转现象发生的频率小于 1950-1986 年. 另外, 2002-2007 年 RDFAI 数值均为正且振
表 1 长周期径流量旱涝划分标准 $\left(\times 10^{8} \mathrm{~m}^{3} / \mathrm{s}\right)$

Tab. 1 Runoff standard of dividing long-cycle drought and flood

\begin{tabular}{rcc}
\hline 标准差 & $5-6$ 月 & $7-8$ 月 \\
\hline-1.0 & 0.1 & 1.2 \\
-0.5 & 0.8 & 2.8 \\
0.5 & 2.2 & 6.0 \\
1.0 & 2.8 & 7.6 \\
\hline
\end{tabular}

表 2 短周期径流量早涝划分标准 $\left(\times 10^{8} \mathrm{~m}^{3} / \mathrm{s}\right)$

Tab. 2 Runoff standard of dividing short-cycle drought and flood

\begin{tabular}{rcccc}
\hline 标准差 & 5 月 & 6 月 & 7 月 & 8 月 \\
\hline-1.0 & $-0.02^{*}$ & $-0.16^{*}$ & 0.6 & 0.4 \\
-0.5 & 0.3 & 0.3 & 1.5 & 1.2 \\
0.5 & 1.0 & 1.3 & 3.2 & 3.0 \\
1.0 & 1.4 & 1.7 & 4.0 & 3.8 \\
\hline
\end{tabular}

* 表示无显著偏早年.

表 $31950-2007$ 年间汛期长周期 RDFAI 最高 (低) 前 6 a 及其标准化径流量分布

Tab. 3 The first 6 highest( lowest) rainy season long-cycle RDFAI and standardization runoff distribution during 1950-2007

\begin{tabular}{cccccccc}
\hline \multicolumn{3}{c}{$R D F A$ 最高 } & & \multicolumn{3}{c}{ RDFAI 最低 } \\
\cline { 1 - 1 } \cline { 7 - 8 } 年份 & $5-6$ 月 & $7-8$ 月 & & 年份 & $5-6$ 月 & $7-8$ 月 \\
\hline 1982 & -0.94 & 1.20 & & 1964 & 3.58 & -0.53 \\
2007 & -0.73 & 1.68 & & 1985 & 1.10 & -0.70 \\
1968 & -0.90 & 0.91 & & 1959 & 0.49 & -1.20 \\
1965 & -0.61 & 0.87 & & 1973 & 1.04 & -0.45 \\
1950 & -0.18 & 1.48 & & 1971 & 1.18 & -0.31 \\
1996 & -0.69 & 0.49 & & 1974 & 0.36 & -0.84 \\
\hline
\end{tabular}


荡增加, 表明旱转港的趋势渐强 (图 1). 因此, 淮河流域长周期旱涝急转现象在由向以旱转涝为主导转变, 且 强度逐渐增大.

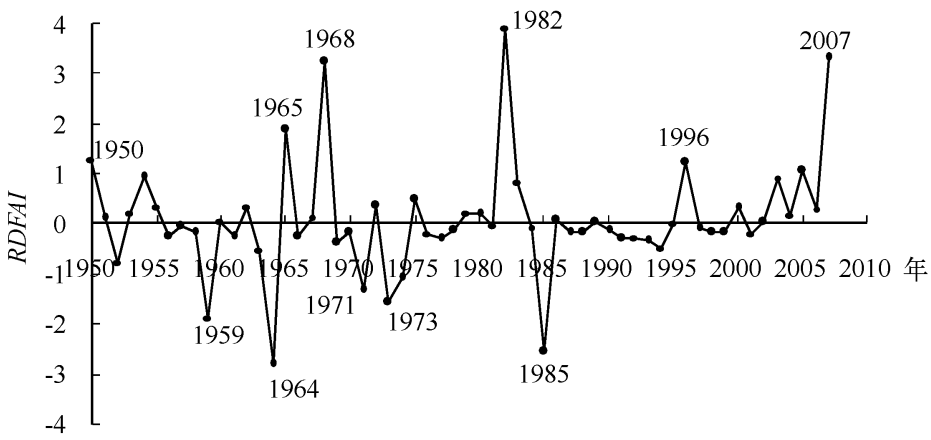

图 1 淮河流域 1950-2007 年汛期长周期径流旱涝急转指数 ( RDFAI) 时间序列

Fig. 1 Inter-annual variation of the rainy season long-cycle RDFAI during 1950-2007 in Huaihe River Basin

另外,从 1950-2007 年淮河地区 5-6 月和 7-8 月的标准化径流分布 (表 4) 可知:在 1950-2007 的 58 a 间共计发生全旱和全涝 21 次,其中全旱 14 次,全涝 7 次,且其强度都很大. 另外,在 1950-1986 的 37 a 间,全旱、全涝共计发生 11 次,约 3.36 a/次,而在 1987-2007 的 $21 \mathrm{a}$ 间,全旱和全涝共计发生 10 次, $2.1 \mathrm{a} /$ 次. 因此,全旱和全涝现象在 1986 年以后更为频繁.

表４1950－2007 年间汛期全旱、全涝年标准化径流量分布

Tab. 4 The rainy season standardization runoff distribution of total drought and total flood during 1950-2007

\begin{tabular}{crrrrr}
\hline $1950-1986$ 年 & $5-6$ 月 & $7-8$ 月 & $1987-2007$ 年 & $5-6$ 月 & $7-8$ 月 \\
\hline 1954 & 0.77 & 3.13 & 1988 & -0.76 & -1.03 \\
1956 & 2.91 & 1.95 & 1991 & 2.45 & 1.67 \\
1961 & -0.78 & -1.19 & 1992 & -0.86 & -1.32 \\
1963 & 2.09 & 1.04 & 1994 & -0.53 & -1.31 \\
1966 & -0.86 & -1.27 & 1995 & -0.67 & -0.66 \\
1967 & -0.87 & -0.66 & 1997 & -0.90 & -1.04 \\
1976 & -0.51 & -0.82 & 1998 & 1.37 & 1.08 \\
1978 & -1.02 & -1.24 & 1999 & -0.81 & -1.10 \\
1978 & -0.90 & -0.55 & 2001 & -1.01 & -1.35 \\
1980 & 0.64 & 0.95 & 2003 & 0.42 & 2.00 \\
1981 & -0.95 & -1.00 & & & \\
\hline
\end{tabular}

可见,近 $21 \mathrm{a}$ 来, 旱涝急转的振荡频数较以前表现出减少的趋势,而全旱和全涝的频数却表现出增加的 趋势. 这表明淮河流域汛期长周期旱涝急转在向全旱或全涝过渡,这也是导致 1986 年以来 $R D F A I$ 年际振荡 相对较为平稳的原因之一.

2.1 .2 短周期径流旱涝急转特征 高 $R D F A I$ 年 $6 、 7 、 8$ 月标准化径流量均分别大于对应的 $5 、 6 、 7$ 月,低 $R D F A I$ 年则相反 (表 5). 高 RDFAI 同样也对应着汛期径流短周期的旱转涝, 低 RDFAI 对应着涝转旱. 其中, 高指数 6-7 月 (旱转涝) 表现最为突出, 6 月标准化径流量有 5 a 小于 -0.5 , 偏旱, 7 月中的 6 a 均大于 0.5 , 偏涝,且其中有 2 年显著偏涝, 1 年特涝. 其它指数年份表现则不甚显著.

同长周期选取规则一样,短周期 5-6 月选取 1971、1980 和 1984 年为典型早转涝年, 1969、1973 和 1977 年为典型涝转早年, 即短周期 5-6 月旱涝急转发生频率为 9.67 a/次;6-7 月选取 1950、1965、1968、1996、 2005 和 2007 年为典型旱转涝年, 1964 年为典型涝转旱年, 即短周期 6-7 月旱涝急转发生频率为 $8.29 \mathrm{a} /$ 次; 
7-8 月选取 1982 和 2004 年为典型早转涝年, 2000 年为典型涝转早年, 即短周期 7-8 月旱涝急转发生频率 为 $19.33 \mathrm{a} /$ 次.

表 5 1950-2007 年 5-8 月相邻月短周期 RDFAI 最高(低)前 $6 \mathrm{a}$ 及其标准化径流量分布

Tab. 5 The first 6 highest( lowest) short-cycle RDFAI and standardization runoff distribution during 1950-2007

\begin{tabular}{|c|c|c|c|c|c|c|c|c|c|c|c|c|c|c|c|c|c|}
\hline \multicolumn{3}{|c|}{ RDFAI 最高 } & \multicolumn{3}{|c|}{ RDFAI 最低 } & \multicolumn{3}{|c|}{ RDFAI 最高 } & \multicolumn{3}{|c|}{$R D F A I$ 最低 } & \multicolumn{3}{|c|}{ RDFAI 最高 } & \multicolumn{3}{|c|}{ RDFAI 最低 } \\
\hline 年份 & 5 月 & 6 月 & 年份 & 5 月 & 6 月 & 年份 & 6 月 & 7 月 & 年份 & 6 月 & 7 月 & 年份 & 7月 & 8 月 & 年份 & 7 月 & 8 月 \\
\hline 1984 & -0.53 & 1.18 & 1977 & 1.42 & -0.67 & 1968 & -0.78 & 0.96 & 1964 & 2.03 & -0.64 & 2004 & -0.64 & 0.22 & 2000 & 1.07 & -0.54 \\
\hline 1980 & -0.32 & 1.18 & 1969 & 2.12 & -0.32 & 1965 & & 0.69 & 1959 & 0.15 & -1.02 & 1982 & -0.11 & 2.32 & 1996 & 1.17 & -0.26 \\
\hline 2000 & -0.97 & 0.29 & 1950 & 0.39 & -0.55 & 1950 & -0.55 & 1.60 & 1970 & 0.29 & -0.50 & 1963 & 0.06 & 1.86 & 1960 & 0.34 & -0.56 \\
\hline 1989 & -0.30 & 0.72 & 1958 & 0.32 & -0.60 & 2005 & -0.52 & 0.78 & 1985 & 0.29 & -0.48 & 1953 & -0.68 & -0.03 & 1971 & 0.21 & -0.78 \\
\hline 1971 & -0.21 & 1.89 & 1952 & 0.78 & -0.24 & 2007 & -0.54 & 2.16 & 1974 & 0.05 & -1.15 & 1984 & 0.09 & 0.69 & 1972 & 0.91 & 0 \\
\hline 1975 & -0.20 & 0.53 & 1973 & 2.22 & -0.14 & 1996 & -0.43 & 1.17 & 1963 & 1.55 & 0.06 & 1974 & -1.15 & -0.41 & 2006 & 0.18 & -0.37 \\
\hline
\end{tabular}

整体来看, 5-6 月 RDFAI 在 $1969-$ 1989 年振荡频繁, 但强度不大; 6-7 月 RDFAI 在 1964-1974 年内振荡频繁且更为 剧烈,1999 年以后频数亦有振荡增加的趋 势; 7-8 月 RDFAI 整体都趋于平稳, 仅在 2000 年有了 1 次较为明显的振荡. 结合表 3 来看,短周期径流早涝急转以在 6-7 月表 现最为显著 (图 2). 另外, 短周期 6-7 月 $R D F A I$ 的振荡变化与长周期 $R D F A I$ 的振荡 变化趋势相似.

分析 1950-2007 年淮河地区 5-8 月 份短周期相邻月标准化径流分布可知, $58 \mathrm{a}$ 中 5-6月、6-7 月、7-8 月发生全涝、全旱 共计发生 70 次, 0.83 a/次. 其中, 全旱 46 次,全涝共计发生 24 次, 全旱频数约为全涝 频数的两倍. 全旱 46 次, 其中 5-6月 17 次,即 $3.41 \mathrm{a} /$ 次;6-7 月 13 次,即 $4.46 \mathrm{a} /$ 次; $7-8$ 月 16 次,即 $3.63 \mathrm{a} /$ 次. 其中, 5-6 月和 6-7 月无连续两月小于 $-1,7-8$ 月有 $7 \mathrm{a}$ 连续两月标准化径流量都小于 -1 , 显著偏 旱, 即全旱在 7-8 月表现明显; 全涝共计发 生 24 次,其中 5-6月 5 次,即 11.6 a/次; $6-7$ 月 6 次,即 $9.67 \mathrm{a} /$ 次; $7-8$ 月 13 次, 即 $4.46 \mathrm{a} /$ 次. 其中, 5-6 月标准化径流量有 $2 \mathrm{a}$ 连续两月大于 1 , 显著偏早, $6-7$ 月有 $3 \mathrm{a}$ 连续两月大于 1 , 显著偏早, 而 7-8 月 13 个 全涝年中有 $6 \mathrm{a}$ 连续两月大于 1 , 显著偏涝, 即全涝亦在 7-8 月表现明显. 另外, 7-8 月 全涝年中其中有 4 个月标准化径流量大于
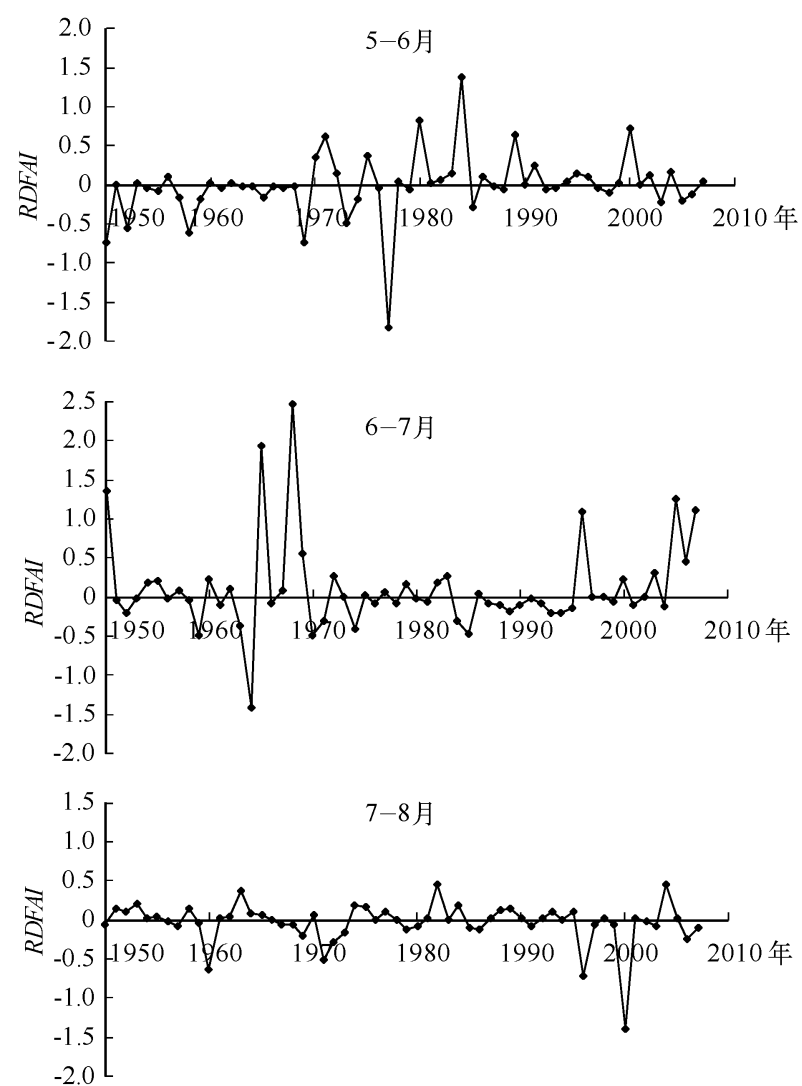

图 2 淮河流域 1950-2007 年 5-8 月相邻月 间短周期 RDFAI 时间序列

Fig. 2 Inter-annual variation of short-cycle $R D F A I$ during 1950-2007 in Huaihe River Basin

3 , 属于特涝, 而这 4 个月也分别对应了淮河历史上的典型重涝年 1954 、1956、1964 和 1991 年 ${ }^{[18]}$.

另外,在 1950-1986 年的 $37 \mathrm{a}$ 间,5-6 月全旱、全涝共计发生 14 次,2.64 a/次,6-7 月全旱、全涝共计 
发生 12 次、3.08 a/次, 7-8 月全旱、全涝共计发生 17 次、2.18 a/次. 而在 1987-2007 年的 $21 \mathrm{a}$ 间, 5-6 月 全旱、全涝共计发生 8 次、 $2.63 \mathrm{a} /$ 次, 6-7 月全旱、全涝共计发生 7 次、3 a/次, 7-8 月全旱、全涝共计发生 12 次 $1.75 \mathrm{a} /$ 次. 近 $21 \mathrm{a}$ 来,短周期旱涝急转振荡频数较以前有所减少,而全旱和全涝的三个短周期都表现 出增加的趋势, 其中以 7-8 月增加明显. 这表明淮河流域汛期短周期径流旱涝急转同样有向全旱或全涝过 渡的趋势.

\section{2 旱涝急转与径流长期变化的关系}

2.2. 1 讯期径流变化基本特征 淮河年径流量总体上呈微弱减少的趋势,径流量年际波动剧烈,最大年径流 量 $\left(2003\right.$ 年, $\left.24.2 \times 10^{8} \mathrm{~m}^{3}\right)$ 约是最小年径流量 $\left(1978\right.$ 年, $\left.1.0 \times 10^{8} \mathrm{~m}^{3}\right)$ 的 24 倍. 年径流与汛期径流的年代际 变化曲线 (图 3) 反映出汛期径流量年代际变化趋势与年径流年代际变化趋势基本保持一致,并同样呈现整 体随年代微弱减少的趋势. 另外, 平均汛期径流量约占平均年径流量的 $56.2 \%$. 可见,淮河流域年径流量主 要集中在汛期,其径流量变化是影响年径流量变化趋势的关键因素.

从图 4 可以看出,该序列可分为如下几个时段 (持续时间为 $4 \mathrm{a}$ 以上) : 三个显著的枯水段即 $1957-$ 1962 年、1975-1979 年和 1991-1995 年,一个显著的丰水期即 1953-1957 年,三个显著的动荡期即 19621975 年、1979-1991 年和 1996-2007 年,动荡期内持续丰水和持续枯水时段不长 (不超过 4 a), 丰枯交替出 现.此外,淮河流域径流量年际之间持续枯水期较持续丰水期长.

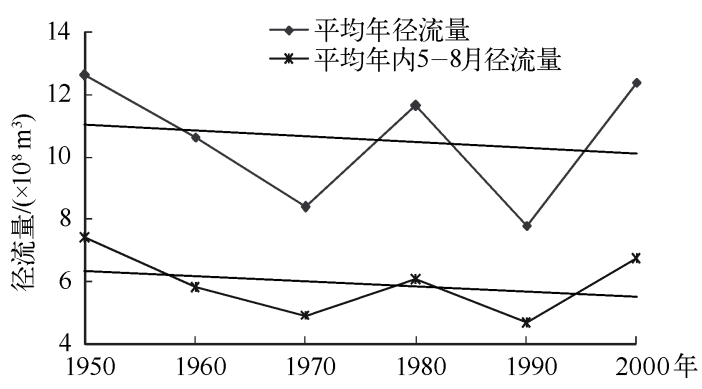

图 3 年径流与汛期径流年代际变化曲线

Fig. 3 The decadal variation curve of annual runoff and annual runoff during the rainy season

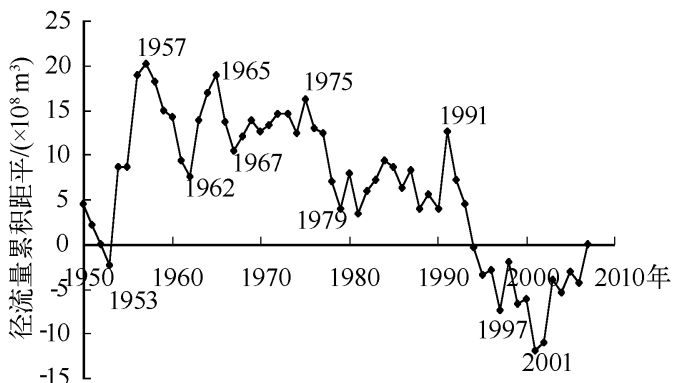

图 4 汛期径流量累积距平年际变化

Fig. 4 The inter-annual variation of accumulated runoff anomaly during the rainy season

2.2.2 汛期径流变化与旱涝急转 长周期旱涝急转变化与汛期径流年际变化的关系表明, 1950-1986 年 (图 5a) 径流量呈减少趋势,长周期 RDFAI 则基本保持不变的趋势; 1987-2007 年(图 5b) 径流量呈增加趋 势,且长周期 RDFAI 的增加趋势亦表现强烈. 1987-2007 年两者表现出了较为一致的变化趋势,尤其从 2002 年开始, RDFAI 变化均为正,两者变化的一致性越发明显 (图 5b). Pearson 相关性分析表明,长周期
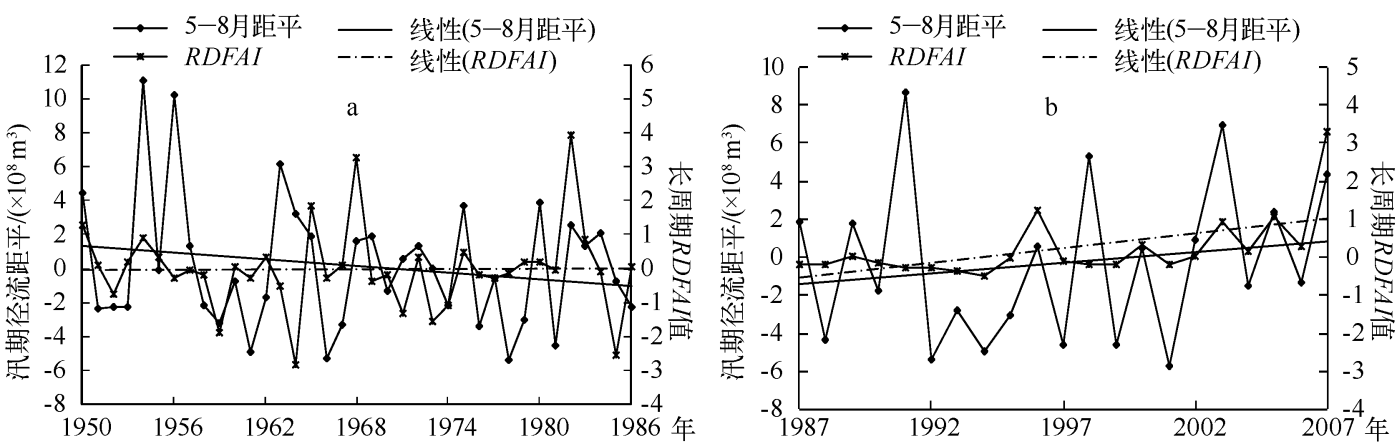

图 5 1950-2007 长周期 RDFAI 与汛期径流距平时间序列

Fig. 5 Inter-annual variation of long-cycle RDFAI and runoff anomaly during the rainy season during 1950-2007 
$R D F A I$ 与径流距平的相关系数在 $1950-1986$ 年、1987-2007 年、2002-2007 年分别为 $0.207 、 0.417 、 0.557$, 说明两者变化的一致性趋势在 1987-2007 年相对于 1950-1986 年更强,而在 2002-2007 年两者变化的一 致性趋势最强. 而 2000s 汛期径流量的增加主要在 7、8 月, 5、6 月径流量则为减少趋势 (图 6). 因此,长周期 旱转涝、短周期 6-7 月旱转涝趋势渐强是导致 2000s 汛期径流量增加的主要原因之一.

其次,长周期旱涝急转 11 个典型旱涝急转年中有 $9 \mathrm{a}$ 在汛期径流的动荡期,而在枯水期或丰水期年份 则基本没有发生. 此外,短周期旱涝急转典型年也基本集中在汛期径流的动荡期. 这说明旱涝急转变化是导 致汛期径流量的年际丰枯振荡变化的主要原因.
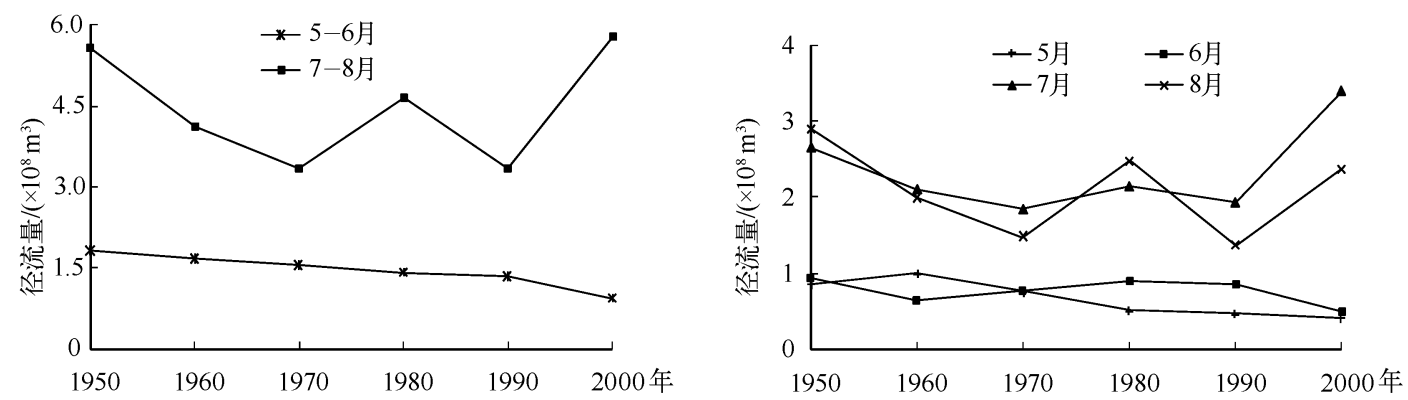

图 6 汛期径流年代际变化曲线

Fig. 6 The decadal variation curves of runoff during the rainy season

\section{3 结论与讨论}

1) 长周期旱涝急转特征分析中, 高 RDFAI 对应着径流的旱转涝, 低 RDFAI 对应着径流的涝转旱. RDFAI 指数变化存在较大的年际差异,总体上看, RDFAI 在 1986 年前比 1986 年后振荡更为频繁, 尤其是从 2000 年开始振荡趋势加剧. 这与王胜等 ${ }^{[15]}$ 对淮河流域降水旱涝急转现象的研究结果相吻合. 短周期径流旱 涝急转指数中,高 RDFAI 也同样对应着径流的旱转涝,低 RDFAI 对应着径流的涝转旱. 其中, $6-7$ 月短周期 旱涝急转的旱转涝振荡变化最为明显,且短周期 6-7 月的旱涝急转的振荡变化与长周期旱涝急转的振荡 变化趋势相似. 另外,1986 年以后,淮河流域汛期长、短周期旱涝急转整体在向全旱或全涝过渡.

2) 分析淮河流域旱涝急转现象表明,长周期旱转涝与短周期 6-7 月旱转涝在 1990s 以后占主导且有 逐渐增强的趋势, 这是导致 2000s 汛期径流量增加的主要原因之一. 其次, 由于长、短周期旱涝急转典型年份 基本都出现在汛期径流的动荡期,在枯水期或丰水期基本没有发生典型的旱涝急转现象. 因此,径流旱涝急 转变化是导致汛期径流量的年际丰枯振荡变化主要原因.

3) 汛期 5-8 月是江淮流域降水量最多的时期,集中降水是淮河流域水资源的重要来源,也是主要农作 物生长的关键时期,受东亚季风的影响淮河流域降水季节内分配异常以及地形等因素共同导致了淮河流域 极易发生旱涝急转现象,对淮河流域的农业生产造成了严重影响. 因此,需对淮河流域的旱涝急转现象进行 进一步的深人研究,如结合淮河流域降水资料或大气环流变化等来共同研究此现象变化规律, 以及着重对 旱涝并存中旱与涝交替的分布规律进一步深人研究, 以实现该地区水资源优化配置, 为农业生产提供有效 可靠的科学依据.

致谢: 在文章的写作过程中,得到了中国科学院大气物理研究所李建平研究员和南京信息工程大学吴志伟 工程师的大力支持和帮助,在此表示衰心的感谢!

\section{4 参考文献}

[1] 毛信康. 淮河流域水资源可持续利用. 北京: 科学出版社, 2006: 9-17.

[2] 张效武, 徐维国, 施宏江等. 安徽省旱涝急转规律的认识与研究. 中国水利, 2007, (5) : 40-42.

[ 3 ] Arnell NW. Climate change and global water resource. Global Environmental Change, 1999, 9 (Suppl. ) : 31-49. 
[ 4 ] Frich P, Alexander LV, Della-Marta P et al. Observed coherent changes in climatic extremes during the second half of the twentieth century. Geophysical Research Letters, 2002, 19: 193-212.

[ 5 ] Aguilar E, Peterson TC, Obando R et al. Changes in precipitation and temperature extremes in central America and northern south America, 1961-2003. Geophysical Research Letters, 2005, 110: D23107(doi : 10. 1029/2005JD006119).

[ 6 ] Zhai PM, Zhang XB, Wan H et al. Trends in total precipitation and frequency of daily precipitation extremes over China. Climate, 2005, 18: 1096-1108.

[ 7 ] Menzel L, Burger G. Climate change scenarios and runoff response in the Mulde catchment( Southern Elbe, Germany). Journal of Hydrology, 2002, 267 : 53-64.

[ 8 ] Pruski FF, Nearing MA. Runoff and soil loss responses to changes in precipitation: a computer simulation study. Journal of Soil and Water Conservation, 2002, 57(1): 7-16.

[ 9 ] $\mathrm{Wu} \mathrm{ZW,} \mathrm{Li} \mathrm{JP,} \mathrm{He} \mathrm{JH} \mathrm{et} \mathrm{al.} \mathrm{The} \mathrm{occurrence} \mathrm{of} \mathrm{droughts} \mathrm{and} \mathrm{floods} \mathrm{during} \mathrm{the} \mathrm{normal} \mathrm{summer} \mathrm{monsoons} \mathrm{in} \mathrm{the} \mathrm{mid-and}$ lower reaches of the Yangtze River. Geophysical Research Letters, 2006, 33 : L05813( doi: 10. 1029/2005GL024487).

[10] Karl TR, Knight RW, Plummer N. Trends in high-172 observed climate variability and change frequency climate variability in the twentieth century. Nature, 1995, 377: 217-220.

[11] Dai A, Trenberth KE, Karl TR. Global variations in droughts and wet spells. Geophysical Research Letters, 1998,25 : 3367-3370.

[12］陶诗言, 徐淑英. 夏季江淮流域持久性旱涝现象的环流特征. 气象学报, 1962, 32(1): 1-10.

[13] 吴志伟, 李建平, 何金海等. 大尺度大气环流异常与长江中下游夏季长周期旱涝急转. 科学通报, 2006, 51(14)： 1717-1724.

[14］吴志伟, 李建平, 何金海等. 正常季风年华南夏季“旱涝并存、旱涝急转”之气候统计特征. 自然科学进展, 2007, 17 ( 12 ) : 1665-1671.

[15] 王 胜, 田 红, 丁小俊等. 淮河流域主汛期降水气候特征及“旱涝急转” 现象. 中国农业气象, 2009, 30(1): 31-34.

[16] 唐 明, 邵东国, 姚成林. 沿淮淮北地区旱涝急转的成因及应对措施. 中国水利水电科学研究院学报, 2007, 5 (1) : 26-32.

[17] 魏凤英. 现代气候统计诊断与预测技术. 北京: 气象出版社, 2007: 49-51.

[18] 汪 斌, 葛荣涁, 罗泽旺. 淮河志第三卷: 淮河水文 - 勘测 - 科技志. 北京: 科学出版社, 2006: 222-228. 